\title{
Visual field rehabilitation in the cortically blind?
}

\author{
RICHARD BALLIET, KATHARINE MT BLOOD, PAUL BACH-Y-RITA
}

From the Martinez Veterans Administration Medical Center, Neurophysiological Therapy Section, Rehabilitation Medicine Service, Martinez, and the University of California at Davis School of Medicine Department of Physical Medicine and Rehabilitation Davis, California USA

SUMMARY Investigators have recently reported that specific practice facilitates the restitution of visual fields in partially blinded humans with lesions to the striate cortex. In order to further evaluate this work, attempts were made to retrain twelve homonymous hemianopic or quadrantanopic patients with similar methods, but under conditions in which possible contaminating experimental variables were controlled, including: (a) reliance on gross subjective impressions, (b) large visual stimuli response variability, (c) changes in detection strategies with practice and (d) compensatory eccentric fixation. The results indicate that visual field increases are not trainable. It is concluded that previous studies should be regarded with caution and the restitution of visual fields after damage to the striate cortex in humans is probably not possible with existing methods.

Traditionally, a lesion to the striate cortex in humans has been thought to result in permanent blindness in its corresponding visual field. ${ }^{1-6}$ However, it has been reported that humans with occipital lesions may have residual vision within their blind field by way of subcortical mechanisms. ${ }^{7-10}$ This residual vision, or alleged "blindsight", is defined as the abillity to localise a visual stimulus, as indicated by the patients upper extremity or eye movements. The patient is typically not aware of actual visual images. These findings in humans correspond to studies which have demonstrated that specific training can apparently cause a certain amount of visual recovery from scotoma in primates partially blinded by striate cortial lesions. ${ }^{1-14}$ Recovery is defined as the ability to increase the accuracy of saccades to spots of light presented in the blind field. No evidence is given, however, that would indicate that the animals actually "visualised" the spots of light.

Perhaps the most intriguing work in this field has been done recently by Zihl and von Cramon with humans. ${ }^{15-17}$ Based on the methods used in the previous studies ${ }^{11-14}$ they found that specific visual training can increase visual function in patients suf-

Address for reprint requests: Dr Richard Balliet, University of Wisconsin Medical School, Department of Rehabilitation Medicine E3/342, University Hospital and Clinics, 600 Highland Avenue, Madison, Wisconsin 53792, USA

Received 25 September 1984 and in revised form 5 February 1985. Accepted 9 February 1985. fering from homonymous field defects due to geniculostriate damage.

The reportedly restored vision seemed to be normal in quality, as determined by peripheral tests of light sensitivity, visual acuity, and colour identification, as well as by subjective patient reports. In addition, these seeming visual field increases occurred during periods of systematic training, whereas normal visual experience has no effect.

Zihl and von Cramon have hypothesised that neural mechanisms are responsible for their visual field recovery results. They suggest that selective attention through training forces the use of the defective field, thus increasing neuronal activity in areas of the striate cortex surrounding the damaged area. They ${ }^{16}$ suggest that the superior colliculus ${ }^{18}$ and the parietal lobes ${ }^{19} 20$ may be involved in the mechanisms of such selective attention. Zihl and von Cramon's results appear to challenge the concept that cortical blindness is irreversible. If their results with human subjects can be replicated by other investigators, it would be more likely that there actually exists mechanisms of neural plasticity in the visual system which are analogous to those that have been postulated by one of us for the functional recovery from physical disabilities. ${ }^{21}{ }^{22}$ In order to further investigate the possibility of visual field rehabilitation, we established an intensive programme of visual field training which was consistent with the elimination of potential intervening experimental variables. 


\section{Methods}

\section{PATIENTS}

Twelve patients with homonymous hemianopia or quadrantanopia resulting from occipital lesions (table IPatients Section) were selected from computed tomography records of the Neurology Service at the Martinez Veterans Administration Medical Center. Diagnosis included ischaemic infarctions or embolic infarctions of the left or right posterior cerebral arteries. All patients were male, except for one female (NM); their ages ranged from 56 to 66 years. The time from onset to the time of training ranged from 5 months to 36 years. Patient selection criteria consisted of only the following requirements: (1) stabilised visual fields for a minimum of 4 months; (2) no ocular pathology; (3) macular sparing (central $2^{\circ}$ ) with normal visual acuity $(\geqslant 20 / 20)$ at near and far; (4) normal extraocular muscle control; (5) cognition, attention, memory, and speech within normal limits; and (6) good upperextremity muscle function (to allow normal sitting balance and the ability to press a hand-held switch during training and testing). Patients were informed that the goal of the study was to determine if visual training could increase their visual fields. They were notified of their results at the end of the study. The number of sessions was determined by patient availability and motivation.

2. VISUAL FIELD TESTING

(a) Static Perimetry
A Goldmann Perimeter was used before and after training to determine static peripheral light sensitivity. All examinations were performed by an experienced examiner who was not involved in patient training. Head stabilisation was provided by either a chin-rest or a full-mouth impression bite-plate depending on experimental conditions (see below). The viewing eye was corrected to $20 / 20$ acuity at $30 \mathrm{~cm}$ distance; the eye which was not being tested was occluded with an eye patch

The patient was light adapted for 10 minutes; afterwards the following instructions were given to the patient: "Please look straight ahead at the small black fixation spot $\left(30^{\prime}\right)$ arc in primary position). You will be asked to determine when you can see brief flashes of light which will be presented in various parts of your visual field. During this time do not look at these lights; keep your eye on the fixation spot." The examiner then remotely centred the patient's pupil in the cross-hairs of the perimeter's viewing telescope (which corresponded to the patients fixation spot). In this manner, ocular alignment was regularly monitored and realigned throughout the sessions.

Under the bite-plate condition the patient was centred during the first session and the coordinates of his bite-plate position ( $\mathrm{X}, \mathrm{Y}, \mathrm{Z}$ axes) were recorded and used thereafter in all further testing and training. If the patient's eye was found not to be in the cross-hairs of the telescope, he was reminded to reposition his eye on the fixation spot (See Discussion).

Perimetric examination included isoptic examinations of

Table 1 Clinical description and training results of patients with cerebral blindness

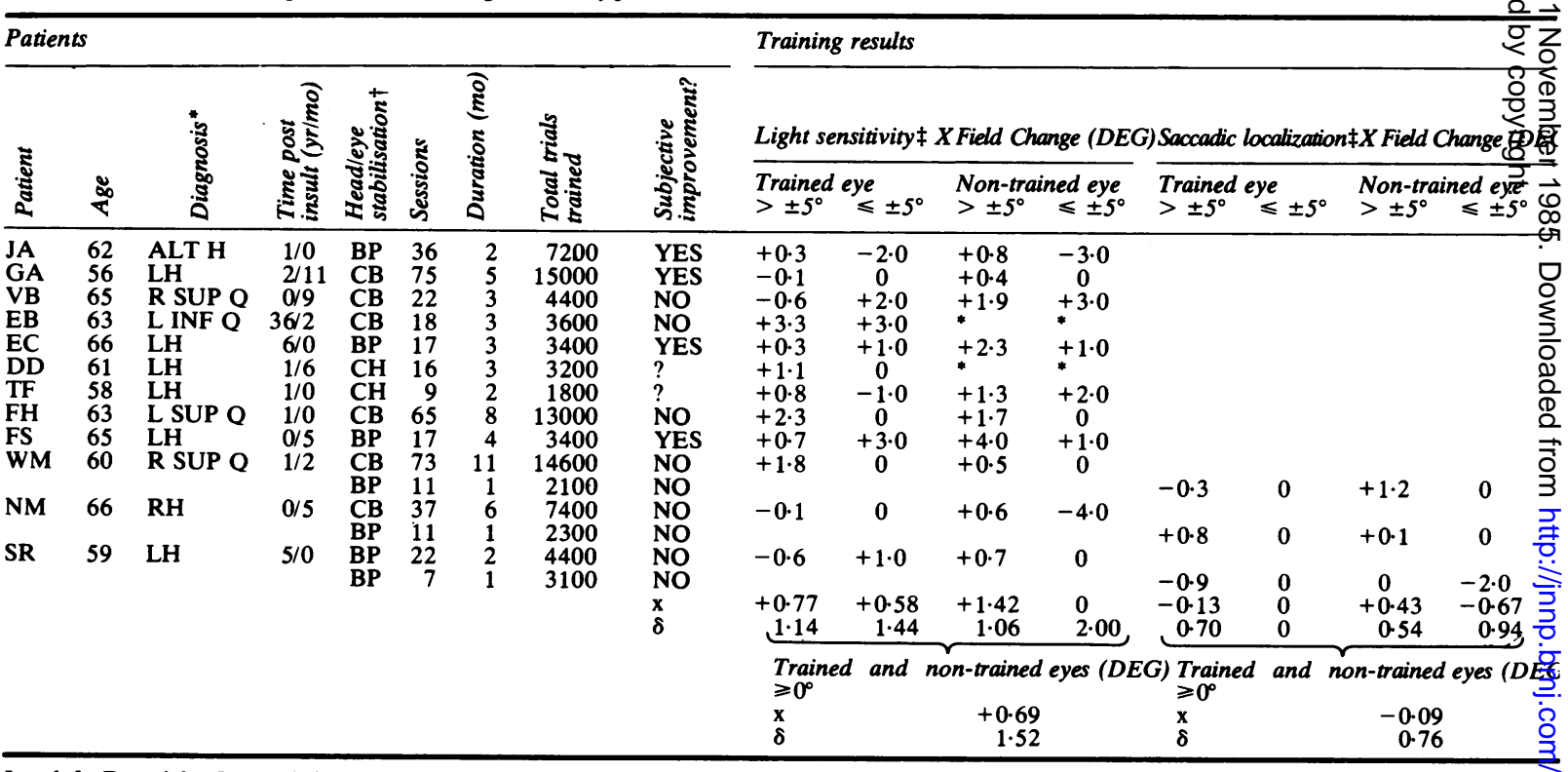

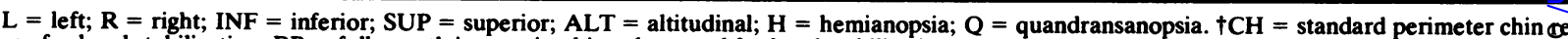

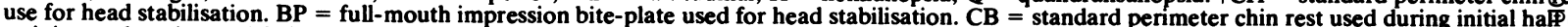

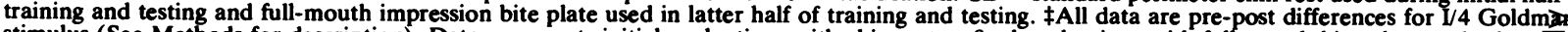

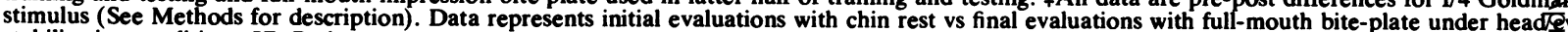

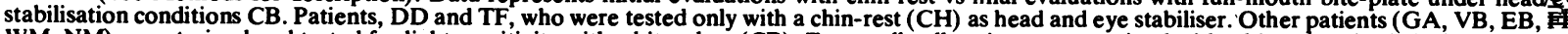

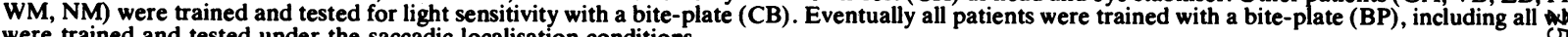
were trained and tested under the saccadic localisation conditions. 
$\mathrm{IV} / 4, \mathrm{I} / 4, \mathrm{I} / 3$, and/or $\mathrm{I} / 2\left(\mathrm{IV}=46^{\prime}\right.$ arc, $\mathrm{I}=6^{\prime}$ arc; $4=320$ $\mathrm{cd} / \mathrm{m}^{2}, 3=100 \mathrm{~cd} / \mathrm{m}^{2}, 2=32 \mathrm{~cd} / \mathrm{m}^{2}$ ) at a background luminance of $3.2 \mathrm{~cd} / \mathrm{m}^{2}$. Each target examination was initially presented statically with an intra-stimulus interval equal to $1.0 \mathrm{~s}$ and an inter-stimulus interval equal to 5-10 s in a visual field which could be seen easily. Thresholds were determined at 25 meridian points using primarily a descending staircase procedure ${ }^{23}$ with random stating points. ${ }^{24}$ Step sizes were $3^{\circ}$ (until first "no"/reversal response) and $1^{\circ}$ (after first "no" response); eight measures were repeated after the second reversal. Ascending staircase examinations were also performed to examine reliability and validity. Good agreement was found between these methods. Blank trials were randomly intermixed to determine bias towards false positive responses. Verbal reminders kept false-positives below 5\%. All patients responses were indicated by the activation of a hand-held switch which caused a buzzer to sound. In order to reduce retinal fading, ${ }^{25} 30$ second rests were given between each meridian test.

\section{(b) Acuity profile perimetry}

Patients FH, WM, and NM also received acuity profile perimetry as a secondary check before and after light sensitivity training (below). A standard Tubinger perimeter and methodology was used as previously described by Johnson, et al. ${ }^{26}$ Monocularly viewed stimuli included four circle and diamond target comparisons $\left(17^{\prime}, 26^{\prime}, 42^{\prime}\right.$ and $66^{\prime}$ of arc diam.@320 cd/ $\mathrm{m}^{2}$ with a background luminance of $3 \cdot 2 \mathrm{~cd} / \mathrm{m}^{2}$ ). A descending staircase design ${ }^{23} 24$ incorporating an $80 \%$ correct response reversal criteria was used to determine threshold values. The patient maintained fixation and made successive determinations as to which stimulus was presented. Six different stimulus positions were tested; these included 2 arbitrarily chosen meridans at $5^{\circ}, 10^{\circ}$ and $20^{\circ}$ past the border of the blind hemifield, as determined by Static Perimetry (above) with the I/4 stimulus.

\section{VISUAL FIELD TRAINING}

(a) Light sensitivity at visual field border. Patients were trained in a manner similar to the method outlined by Zihl and von Cramon. ${ }^{16} 17$ Instead of a Tubinger perimeter, however, a standard Goldmann perimeter was used. In addition, a smaller training stimulus was used because we found that larger stimuli produced substantial intra-patient response variability. The threshold for static light detection for an $\mathrm{I} / 4$ target $\left(6^{\prime}\right.$ arc at $\left.320 \mathrm{~cm} / \mathrm{m}^{2}\right)$, using a background luminance of $3.2 \mathrm{~cd} / \mathrm{m}^{2}$ at varying eccentricities, was repeatedly determined by using a descending staircase procedure $^{23} 24$ in areas of reduced visual sensitivity bordering the apparent scotoma while fixation was maintained (fixation spot $=30^{\prime}$ arc in primary position). Step sizes were $3^{\circ}$ (until first "no"/reversal response) and $1^{\circ}$ (after first "no" response); 10-20 measures were repeated after the second reversal. The patient indicated his responses with a hand activated buzzer. In order to examine later possible interocular transfer, training was given only to the eye which corresponded to the side of the visual field defect. Since patient JA had an altitudinal field defect, the right eye was arbitrarily chosen. Inter-stimulus interval was $5 \mathrm{~s}$, stimulus duration was $1.0 \mathrm{~s}$ and thirty second rests were given every 2-3 minutes. Blank trials were also presented between stimulus trials to keep false positives below $5 \%$. Approximately 25 thresholds were determined each session, with training occurring on a 2-5 day a week basis at the same time each day.

(b) Saccadic localisation of targets presented in scotomous field. Three patients (WM, NM, SR) who failed to respond to the Light Sensitivity training (3.a)above) were also trained to make saccadic eye movements in response to targets presented in their scotomatous field. The method was similar to that used by Zihl. ${ }^{15}$ A standard Goldmann perimeter was used to project the $\mathrm{V} / 4\left(6^{\prime}\right.$ arc at $\left.320 \mathrm{~cm} / \mathrm{m}^{2}\right)$ target stimulus and provide the $3.2 \mathrm{~cd} / \mathrm{m}^{2}$ background. The patient's task was to view monocularly the fixation spot ( $30^{\prime}$ arc) and, at the onset of an auditory signal, to shift his gaze with one eye movement from the fixation spot to the stimulus which was presented for $1 \mathrm{~s}$ duration in differing positions in the hemianopic field. He was reminded to avoid searching for the target beyond the first saccade, regardless of his success in localisation. The patient was then informed as to the meridian in which the stimulus would appear, but he was not informed as to its exact position on the meridian. The stimulus positions in the blind hemifield ranged between $3-50^{\circ}$ from the visual field border as determined by Static Perimetry with a I/4 stimulus (above). Inter-stimulus interval was $5 \mathrm{~s}$; thirty second rests were given every 2-3 minutes. Two to three hundred trials at a total of 1 to 4 meridans (depending upon size of the scotoma) were presented each session on a 2-3 day a week basis at the same time each day.

\section{Results}

(a) Light sensitivity at visual field border. Twelve of the patients were trained under this condition over a period of 2 to 11 months. Table 1 (Training Results Section) shows summarised results for the $1 / 4$ isoptre plot, which was the most peripheral target used in testing and the stimulus found to indicate the greatest consistent field changes (for further explanation see: Discussion; (2) Large visual stimuli response variability). All patients demonstrated only small visual field fluctuations. A range of $-0.6^{\circ}$ to $+3.3^{\circ}$ of fields $> \pm 5^{\circ}$ eccentricities (means were concentrically measured every $5^{\circ}$ ) and a range of $-2 \cdot 0^{\circ}$ to $+3 \cdot 0^{\circ}$ of fields $\leqslant \pm 5^{\circ}$ (means were concentrically measured every $2.5^{\circ}$ ) were found for the trained eyes. A range of $+0.4^{\circ}$ to $+4 \cdot 0^{\circ}$ of fields $>$ $\pm 5.0^{\circ}$ eccentricities and a range of $-4.0^{\circ}$ to $+3.0^{\circ}$ of fields $\leqslant \pm 5.0^{\circ}$ eccentricities were found for the untrained eye. Subtotal means and standard errors were $x=+0.69^{\circ}, \delta=1 \cdot 52: \geqslant 0^{\circ}$ eccentricity. Additional checks with profile perimetry of $\mathrm{FH}$, WM and NM showed no significant changes (not shown). Four patients reported that after training they had experienced very noticeable expansions of their visual fields, six experienced no change, and two were not sure. No patient reported that his vision had declined (see Discussion: (1) Reliance on general subjective impressions section). 


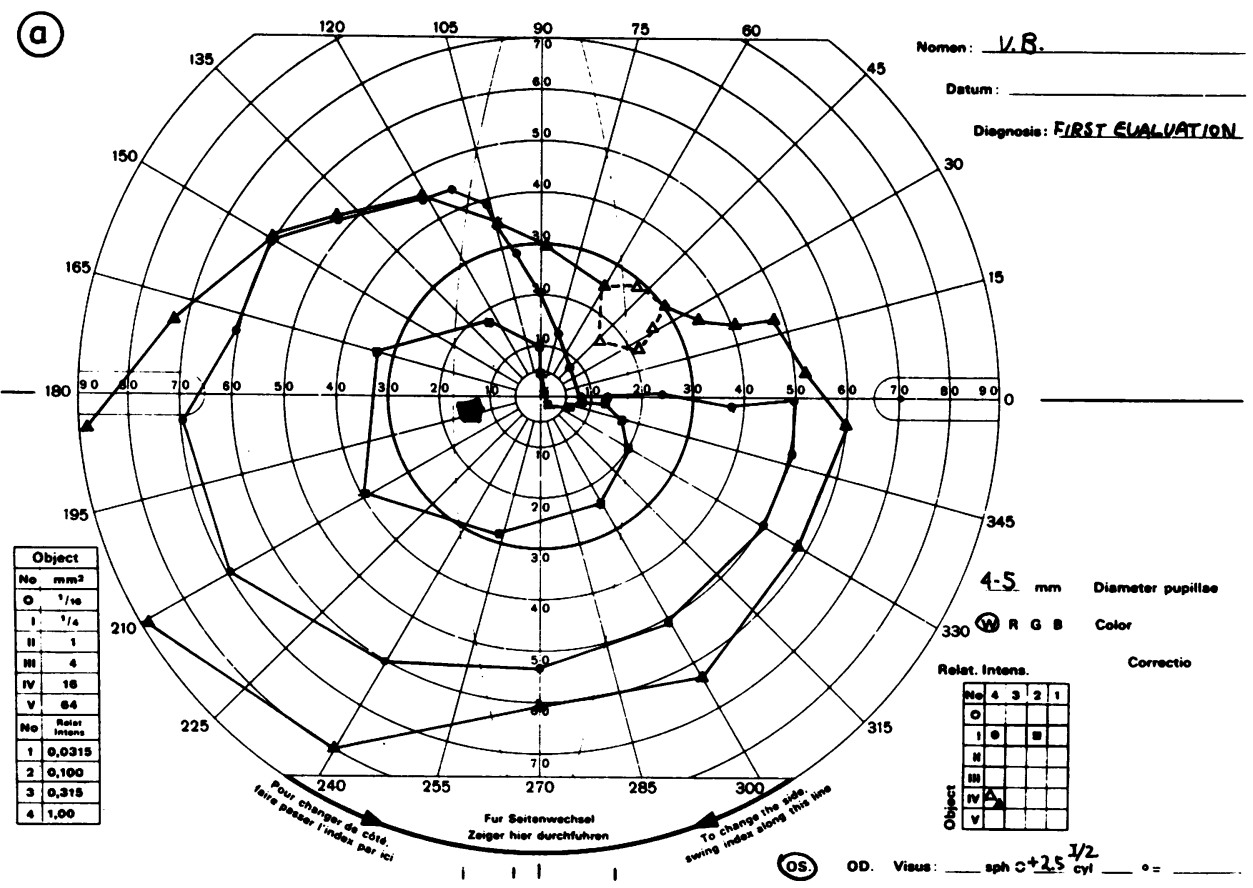

(b)

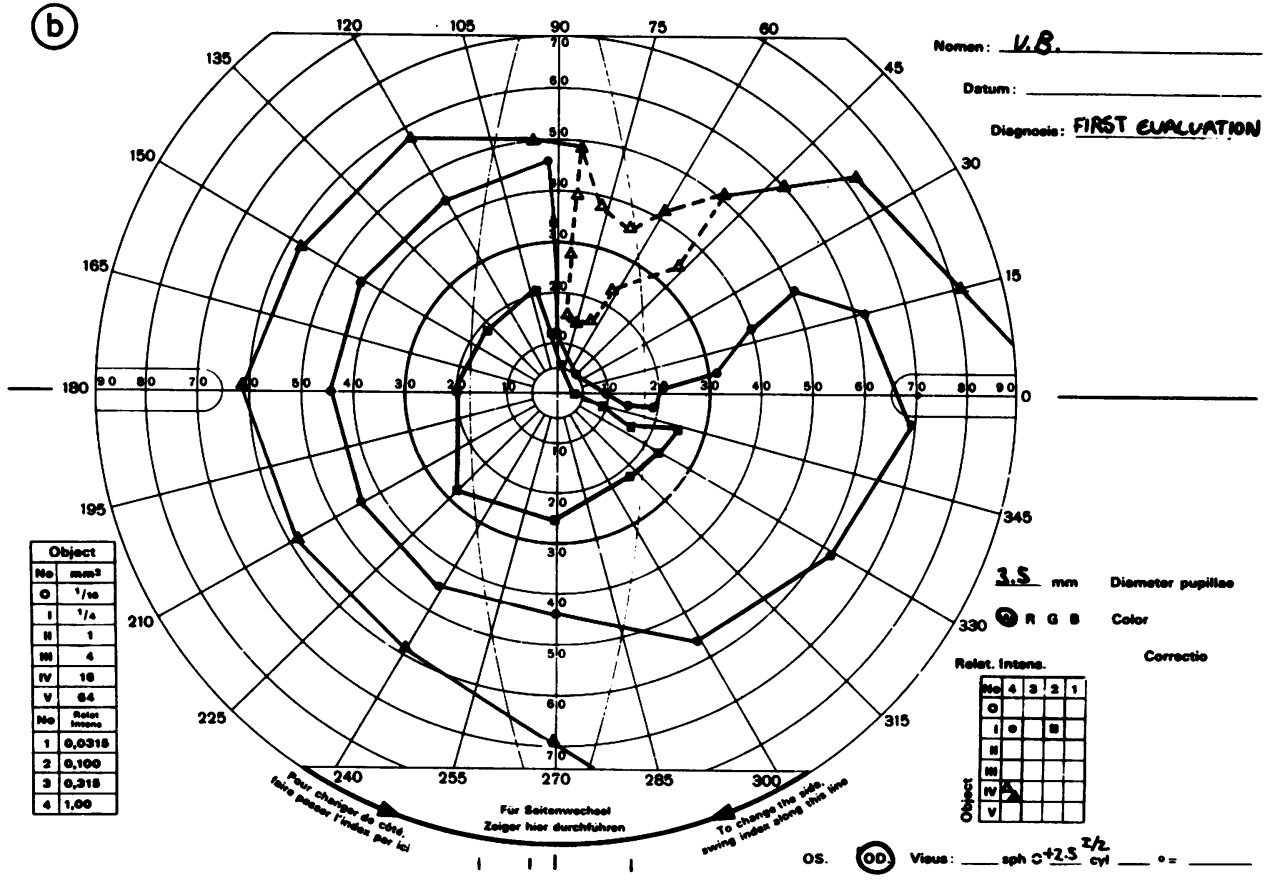


(c)
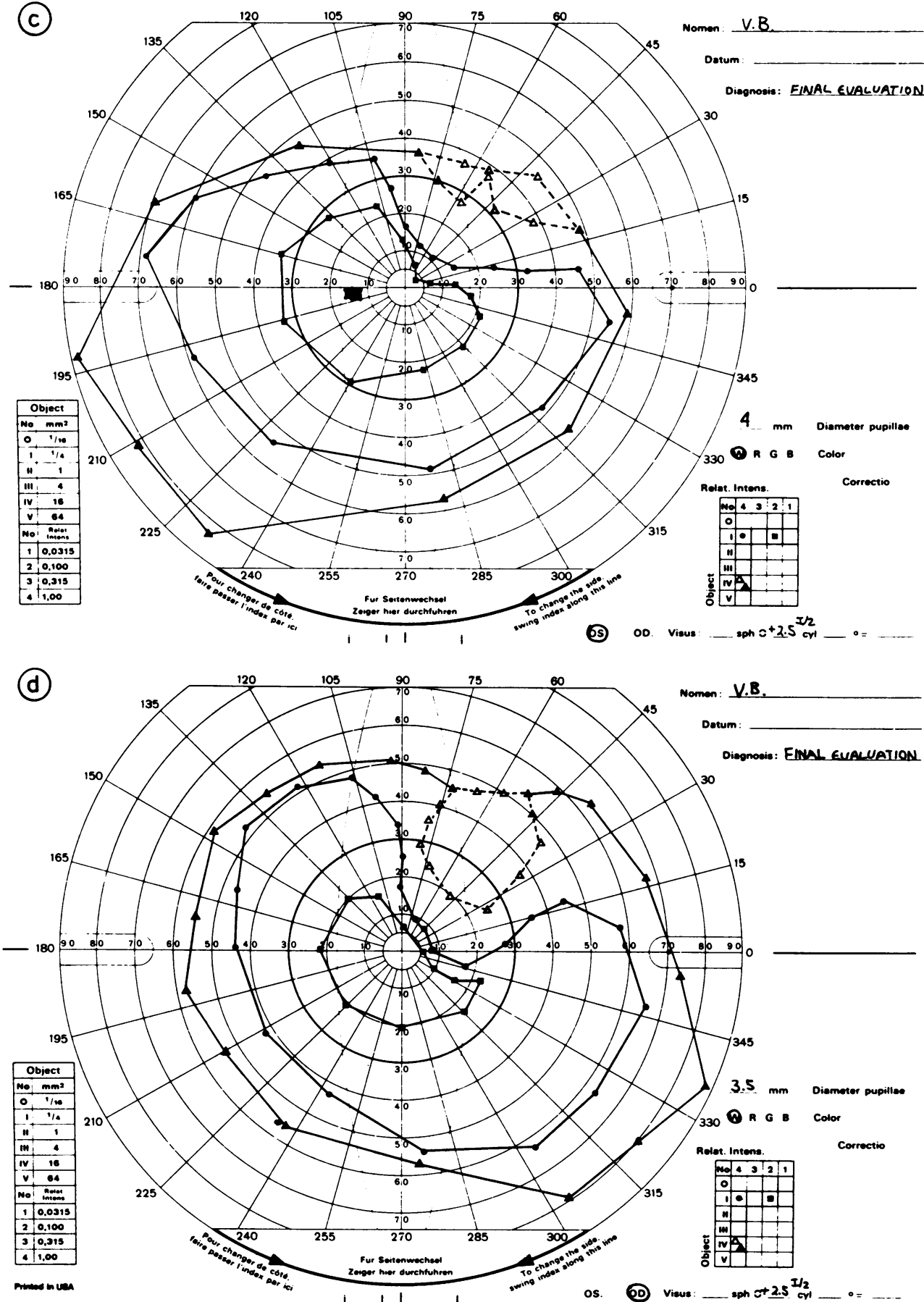

Fig. 1 a-d. Light Sensitivity records of patient V.B. before and after training; a: first evaluation, left eye; $b$ : first evaluation, right eye; $c$ : final evaluation, left eye; $d$ : final evaluation, right eye. Final evaluations are after 4400 trials or 22 sessions over a three month period. Filled dots $(\Theta)=1 / 4$ stimulus; filled squares ( $\square$ ) $=I / 2$ stimulus; both filled and open triangles $(\Delta, \Delta)=I V / 4$ stimulus $\left(I V=46^{\prime}\right.$ arc, $I=6^{\prime}$ arc, $4=320$ $c d / \mathrm{m}^{2}, 2=32 \mathrm{~cd} / \mathrm{m}^{2}$, background $\left.=3.2 \mathrm{~cd} / \mathrm{m}^{2}\right)$. Open triangles $(\Delta)$ indicate approximate range of excessive response variability found during session; all other data points $(\Delta, \Theta, \square)$ represent a response variability range equal to approx $0.3^{\circ}$. A $+2.5 \mathrm{sph}$. lens was used to increase the detectability of the $1 / 2$ stimulus. 
Figure $1 \mathrm{~A}-\mathrm{D}$ shows the Light sensitivity performance of patient VB before and after 22 sessions and 4400 trials. These isoptre records represent the largest apparent increases found in this study. It can be seen that with stimuli I/4 (O) and I/2 ( $\square$ ) (See Methods for target specifications), both eyes showed varying responses. Slight increases (from table I) in central vision $\left(\leqslant \pm 5^{\circ}\right)$ seem to have occurred (OD $\tilde{x}$ $=+2 \cdot 0^{\circ}$, OS $\mathrm{x}=+3 \cdot 0^{\circ}$; some parts of the periphery $\left(> \pm 5^{\circ}\right)$ appeared to increase slightly, while others seem to decrease slightly (OD $\overline{\mathbf{x}}=$ $-0 \cdot 6$, OS $\left.x=1 \cdot 9^{\circ}\right)$. The IV/4 isoptre will be examined in the Discussion, section b: "Large visual stimuli response variability."

(b) Saccadic localisation of targets presented in scotomous field. Three patients (WM, NM, SR) who were also trained over a one month period with the saccadic localisation procedure demonstrated very small visual field changes as measured by the $1 / 4$ target. For the trained eye, perimetry demonstrated a range of $-0.9^{\circ}$ to $+0.8^{\circ}$ for fields of $> \pm 5^{\circ}$ eccentricities (means were concentrically measured every $\left.5^{\circ}\right)$, while no change $\left(0^{\circ}\right)$ was found for fields of $\leqslant$ $\pm 5^{\circ}$ eccentricities (means were concentrically measured every $2 \cdot 5^{\circ}$ ). A range of $0^{\circ}$ to $+1.2^{\circ}$ for fields of $\geqslant \pm 5^{\circ}$ eccentricities and a range of $0^{\circ}$ to $-2 \cdot 0^{\circ}$ for fields of $\leqslant \pm 5^{\circ}$ eccentricities were found for the untrained eye. Subtotal means and standard deviations were $\mathrm{x}=0.09^{\circ}, \delta=0.76: \geqslant 0^{\circ}$. After this training, patients reported no subjective changes in their visual fields.

\section{Discussion}

After approximately 89,000 trials of visual field training $(x=5927$ trials /training series / patient), we found that on the average, no more than a degree of visual field change with either of our Light sensitivity of saccadic localisation training methods (table $\mathrm{I}$ : $\overline{\mathrm{x}}=+0.69^{\circ} ; \overline{\mathrm{x}}=-0.09^{\circ}$, respectively). The variability of our data is probably due to both inter- and intra-individual variabilities that exist in perimetry threshold determinations. ${ }^{27}{ }^{28}$ The reasons for these differences include attentional factors, small head movements of $<1^{\circ}$ with the full impression bite plate, ${ }^{29}$ as well as small fluctuations in fixation, such as cyclotorsional movements ${ }^{30}$ and horizontal and vertical micro-saccades. These small eye movements can conceivably cause "the target image to fall on a retinal blood vessel as well as the next target image measurement to fall on an adjacent and more sensitive area." 27

Our results of less than one degree of apparent visual field change are quite different than those of Zihl and von Cramon. They reported in two of their studies visual field increases ranging from $1^{\circ}$ to $27^{\circ}$ $\left(\mathrm{x}=+9 \cdot 7^{\circ}, \mathrm{N}=26\right)$ over a total number of trials ranging from $180-2130$ per patient. ${ }^{15}{ }^{16}$ In another study, they reported an increase from $1^{\circ}$ to $8^{\circ}(\overline{\mathrm{x}}=$ $+3 \cdot 5^{\circ}, N=10$ ) for visual field eccentricities up to $5^{\circ}$ and increases from $1^{\circ}$ to $14^{\circ}\left(\bar{x}=+7 \cdot 0^{\circ}, N=5\right)$ for visual field eccentricities over $5^{\circ} .^{17}$ Although $\mathrm{Zihl}$ and von Cramon claim that both methods, Light detection and saccadic localization, led to an enlargement of visual field, they also state that "the result of visual field recovery... had clear behavioral consequences, even though the quality of vision has not yet been assessed objectively." 17 We cannot argue that their patients seemed to behave as though their visual fields had increased, but based on our experience, we must question if their patients were in fact trained to expand their visual fields.

In general, our work indicates that Zihl and von Cramon may have relied too heavily on the subjective impressions of their patients. In addition, they may have used stimuli prone to variability, as well as not controlled for eye movement compensation or associated practice effects. The following is a discussion which addresses these potential problems.

(1) Reliance on general subjective impressions. Zihl and von Cramon ${ }^{16}$ indicate that increases in "visual behavior" support the idea of visual fields restitution. Accordingly, their patients reported general increases in impressions of colour, form perception, form discrimination, visual orientation, and reading.

We found, however, that it is perilous to evaluate visual fields in terms of general subjective impressions. For example, four of our patients (JA, GA, 흘 EC, FS) said that they had experienced very noticeable field increases. Similar to Zihl and von Cramon's patients, these patients reported qualitative differences, exemplified in the following observations: "I can now see everything in the room; I can now see people coming at me from out of doorways (when walking down a hallway); I can see cars coming from all directions."

Unfortunately, however, in tests for light sensitivity, these four patients did not have significant visual field differences when compared to those who said they saw "no changes" in their vision $\left(> \pm 5^{\circ}: \overline{\mathrm{x}}=\right.$ $1 \cdot 08^{\circ}, \gamma=1 \cdot 38, \mathrm{~N}=8$ vs. $\overline{\mathrm{x}}=1.04^{\circ}, \gamma=1 \cdot 35, \mathrm{~N}=$ 11 , respectively $t=0.056$; and $\leqslant 5^{\circ}: \bar{x}=0.125, \gamma=$ $1.89^{\circ}, N=8$ vs $\bar{x}=0.450^{\circ}, \delta 1.91, N=10$, respectively $t=0 \cdot 451)$. Therefore, since our patients did not give accurate assessments of their own visual fields, we wonder if Zihl and von Cramon's patients were actually using their assumed new visual field. We suggest the possibility exists that with practice their patients could have been making such determinations by means such as undetected eccentric fixations and/or changes in detection strategies. (see 
below).

(2) Large visual stimuli response variability. Our methods are not an exact replication of Zihl and von Cramon's methods. We used relatively small visual stimuli, for training and testing; they used the following larger targets: $30^{\prime}$ arc for static testing within a $15^{\circ}$ eccentricity; $69^{\prime}$ arc for static testing outside a $15^{\circ}$ eccentricity, and within a $15^{\circ}$ eccentricity dynamic testing (@320 cd/m $\left.\mathrm{m}^{2}\right) ; 116^{\prime}$ arc for dynamic testing greater than a 15 eccentricity (@ $320 \mathrm{~cd} / \mathrm{m}^{2}$ ) and for saccadic localisation training (@ $\left.320 \mathrm{~cd} / \mathrm{m}^{2}\right) .{ }^{15}$ They did not report on the size of their light sensitivity training target, but we assume that it was comparable at approximately 69 to $116^{\prime}$ arc.

We used relatively small stimuli because we found in preliminary work that the above stimuli or any stimulus which approximates more than about $20^{\prime}$ arc @ $>32 \mathrm{~cd} / \mathrm{m}^{2}$ produced greatly varying intrapatient response variability in the more transitional visual fields of reduced sensitivity for example usually peripheral visual fields greater than $5^{\circ}$ eccentricity. In contrast, much less variability was found in areas where the field cut was determined to be sharp, for example foveal visual fields. In addition, unlike targets of less than about $20^{\prime}$, the amount of "large target" variability in the more transitional visual fields of reduced sensitivity also depended upon how much the examiner "pushed" these targets during training and testing. For example, in targets of $46^{\prime}$ arc (IV @ 32-320 cd/m $/ \mathrm{m}^{2}$ ) we found visual field variations of up to $40^{\circ}\left(\overline{\mathrm{x}}=15^{\circ}\right)$ within the same session; however, a stimulus of 6' arc (I@ $\left.32-320 \mathrm{~cd} / \mathrm{m}^{2}\right)$ typically varied no more than 10 degrees $\left(\bar{x}=3 \cdot 1^{\circ}\right)$. Specifically, fig $1, A-D$ shows that our $46^{\prime}$ arc (IV/4) stimulus evoked varying isopter plots $(\triangle)$ for patient VB in the area of his right superior quadranopsia. Although it is not shown, all of the other data points in these figures $(\Delta, 0, \square)$ are averaged within a range of $\pm 3^{\circ}$. Therefore, we decided to use the small $6^{\prime}$ arc (I) targets for all training and tabulated testing results. The $6^{\prime}$ arc target was also used because our patients had no difficulties viewing it well into the periphery of their normal field, (fig 1) and because it has been the target most generally used in visual field plotting with the Goldmann perimeter. ${ }^{31-33}$

It is not completely clear why these relatively large targets cause large response variabilities in areas of reduced sensitivity. Some possible answers to this question may be found in a recent study by Campion, et al. ${ }^{34}$ In a series of experiments that sought to investigate Zihl and von Cramon's methodology, ${ }^{15-173536}$ they found that hemianopic subjects could exhibit increased visual function (including blind sight) when these subjects had only the use of scattered light as a stimulus cue; thus light detection was made possible by scattered light onto unimpaired parts of the visual field. Similar to those of Zihl and von Cramon, all of Campion's stimuli were typically $\geqslant 1^{\circ}$ in visual angle and were presented on (mesopic) backgrounds which were at least as bright as the $3.2 \mathrm{~cd} / \mathrm{m}^{2}$ background used by Zihl and von Cramon and by us in the present study.

These results correspond to photometric measurements of apparent brightness in the scatteredlight distribution around a small point source where it has been found that significant amounts of scattered light (@10\%) occur for stimuli which are $\geqslant 1$ degree.$^{37}$ As stimuli become smaller, the scatteredlight distribution approaches a perfect source image, which is minimally affected by the optical aberrations, diffractions, and imperfections of the eye.

It should be noted that these data are based on young eyes. Receptors receive scattered light after passage through optic media for example, cornea, lens, aqueous humour, vitreous humour, retinal layers and reflectance from pigment epithelium. Light scatter in these media probably increase with age. For further discussion see Frankhauser and Haeberlin..$^{38}$ It is, therefore, possible that Zihl and von Cramon's relatively large stimuli may have confounded their results because such stimuli may not be appropriate as testing and training stimuli. Smaller targets, like the $6^{\prime}$ arc stimuli which we used, are probably less confounded by spurious detections based on scattered light. Relatively large visual stimuli also may lead to increased visual function in the visual fields of transient or reduced sensitivity (vs. sharp field cuts) because hemianopic patients may have areas of residual vision which are inherently susceptible to such stimuli (see Campion et al ${ }^{34}$ for a review of this hypothesis).

(3) Changes in detection strategies with practice. It has been known for some time that practice influences tests of peripheral visual resolution. ${ }^{27}$ 39-42 The effects of practice have been found not to be the same for all subjects, with no consistent reason being found for such variations. This work indicates, however, that typically most subjects plateaued

Table 2 Training results of normal subjects for I/4 Goldman stimulus

\begin{tabular}{lllll}
\hline Subject & \multicolumn{2}{l}{ Light sensitivity $x(D E G)$} & field change & $x$ totals \\
\cline { 2 - 4 } & $0^{\circ}$ & $45^{\circ}$ & $90^{\circ}$ & \\
\hline KB & +4.0 & +3.67 & +1.0 & +2.89 \\
EM & +4.0 & +2.25 & +2.0 & +2.75 \\
LS & +1.83 & +2.58 & +4.67 & +3.03 \\
& & & & $x+2.88$ \\
& & & & $\delta \quad 1.17$ \\
\hline
\end{tabular}

See: Discussion (3) Changes in Detection Strategy with Practice section for complete description. 

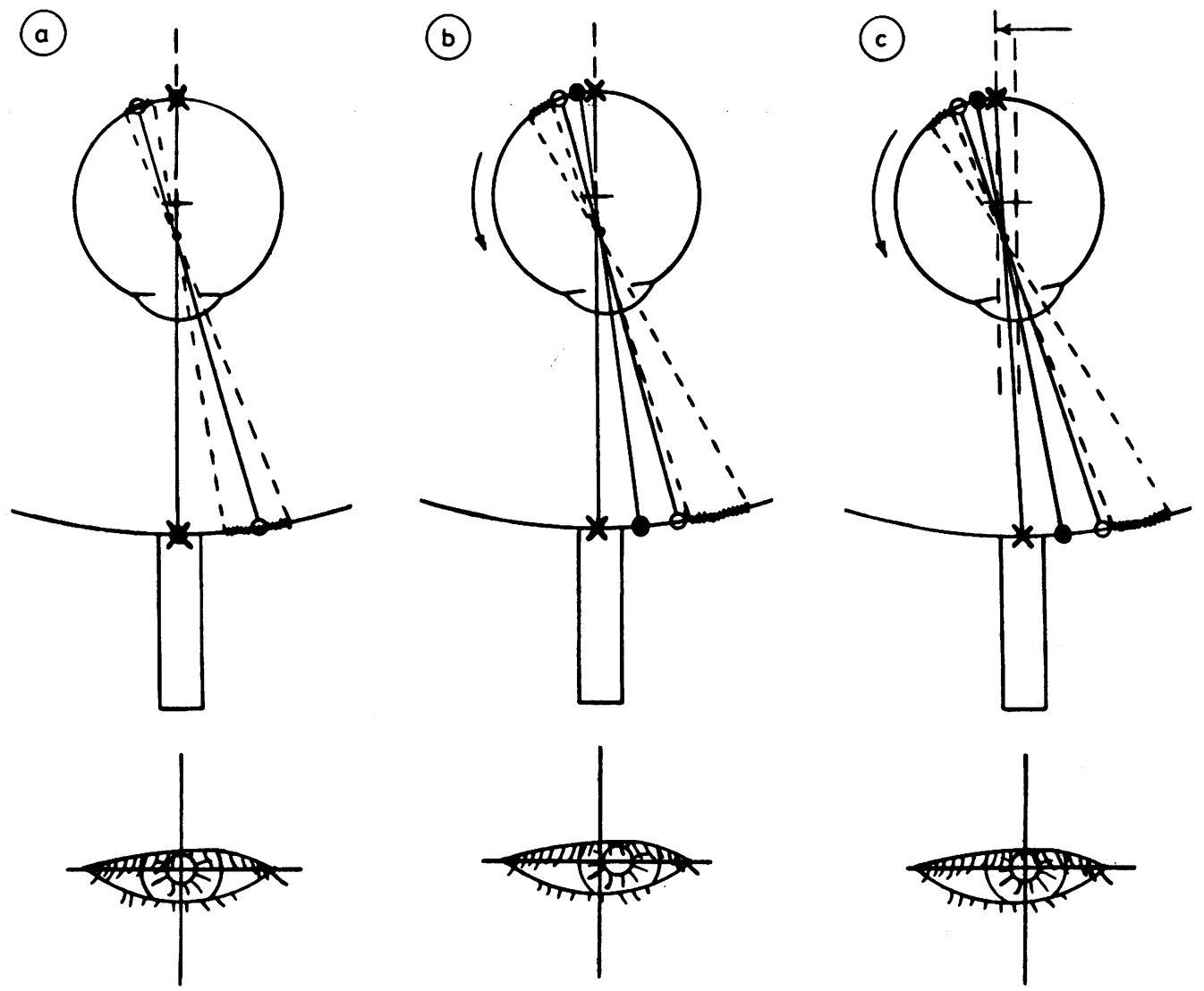

Fig. 2 Representation of potential head/eye stabilisation problems encountered during typical perimeter evaluation methodology. In all three conditions, the patient's eye (in upper segment) is attempting to fixate $(\odot)$ a fixation spot $(X)$ in the perimeter while trying to detect peripheral stimulus $(O)$ as (in lower segment) the examiner views the patients eye and attempts to keep the patient's eye aligned in the cross-hairs of the perimeter telescope. Cross-hatched area $(\mathrm{mmm})$ represents the area of a peripheral field scotoma on retina and corresponding blind visual field as determined by the perimeter. Situation $A$ represents proper fixation with a chin rest or bite-plate; Situation B represents improper and detected eccentric fixation with chin-rest or bite-plate; Situation C represents improper and undetected compensatory eccentric fixation with chin rest only.

within 10 training sessions. In the only paper where the number of sessions is listed, $65 \%$ (9) of $\mathrm{Zihl}^{\prime} \mathrm{s}^{15}$ subjects had no more than 10 training sessions, while only $15 \%$ (2) of these had more than 12 training sessions.

One solution to this problem would be to build in signal detection checks into our experimental design. ${ }^{434}$ Since this solution is very difficult to incorporate into clinical work, we chose a second solution. As a control comparison, we tested and trained three inexperienced, normal subjects between the ages of 19 and 38 years of age under light sensitivity conditions (including the use of a biteplate) identical to those for our patients. Only the right eye was trained and tested. Three different meridians $\left(0^{\circ}, 45^{\circ}, 90^{\circ}\right)$ were trained for seven sessions. We found all three subjects had similar results (table 2); they stabilised within three sessions for an average field change of $\bar{x}=2 \cdot 88^{\circ}, \delta=1 \cdot 17$.

Practice effects could have in part contributed to Zihl and von Cramon's results since some of their changes occurred within a few sessions. Practice effects could also explain the relatively larger amounts of field change we found for patients EB, FH, and FS under the light sensitivity condition. On the other hand, they do not explain the results of patients JA and NM under light sensitivity conditions. These patients seemed to get slightly worse, particularly at eccentricities of $\leqslant \pm 5^{\circ}$.

(4) Compensatory Eccentric Fixation. During our 


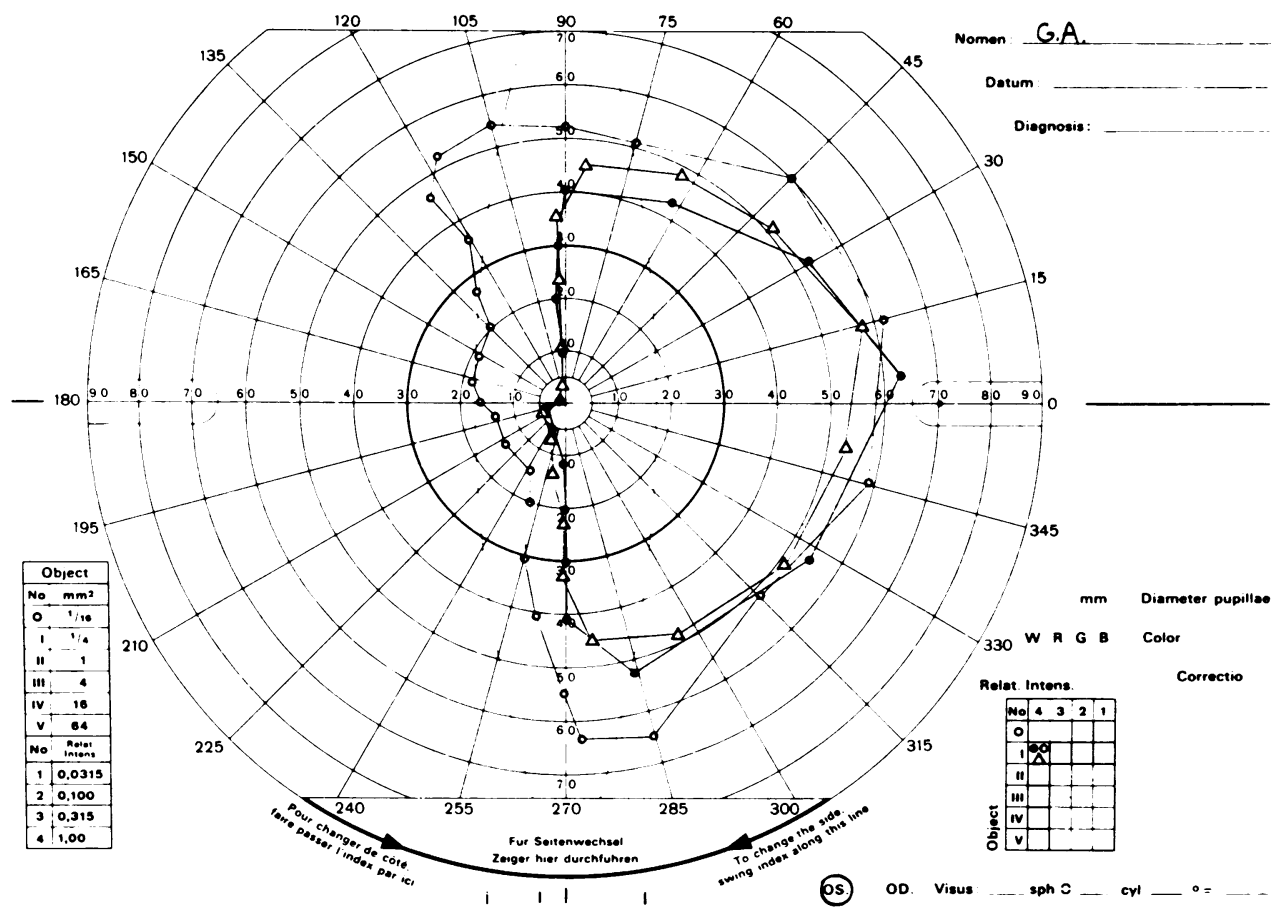

Fig. 3 Composite light sensitivity thresholds of $I / 4$ stimulus ( $6^{\prime}$ arc at $320 \mathrm{~cd} / \mathrm{m}^{2} ; 3 \cdot 2 \mathrm{~cd} / \mathrm{m}^{2}$ background) for the left eye of patient $G A$. Closed dot $(\bullet)$ represents initial evaluation and open dot $(\bigcirc)$ represents mid-training evaluation, both with chin-rest headleye stabilisation. Open triangles $(\Delta)$ represent final post-training evaluation under full mouth impression bite-plate head stabilisation method.

initial training of patients, we used, as did Zihl and von Cramon, ${ }^{16}$ a chin-rest method of head/eye stabilisation with a perimeter-telescope monitoring system. We found with some of our patients, that it was necessary to adjust constantly their head position so that the eye would maintain its position in the cross-hairs of the perimeter's telescope (as described in Methods). In addition, during initial training we also apparently found significant training effects in a few patients (GA, VB, WM) which were comparable to those reported by some of $\mathrm{Zihl}$ and von Cramon's more successful patients, that is visual field increases of $15-25^{\circ}$.

On the other hand, Dr Chris Johnson at the Department of Ophthalmology, University of California at Davis School of Medicine (personal communication) suggested to us that it was conceivable these patients might have been making compensatory eccentric fixations. We define eccentric fixations as any detectable (with the perimeter telescope) rotations of the eye which cause an abnormality in alignment of the fixation spot as imaged on the fovea. These eye movements may be additive within a day's session (intra-) or over many day's sessions (inter-). Such eye movements can increase the patient's field of view to one side, but not his visual field. In support of this idea, Meienberg, et al have reported that homonymous hemianopsia patients who had occipital lesions "employ[ed] a set of compensatory strategies [may be conscious or unconscious] to find and fixate objects ... in the seeing hemifield. [They] undershot the target to prevent losing it in the blind hemifield, then held it off-fovea on the seeing side of the macula." 45

We now believe that chin-rest head stabilisation, as is commonly used in perimetry can in fact cause specific eye monitoring difficulties as well as the potential for eccentric fixations which can easily pass undetected by the examiner, as depicted in fig. 2 . The assumption is made that on the first day of testing and previous to training, the patient can make, at best, a normal non-eccentric foveal fixation. In the worst case the first day fixation may be eccentric, but all future fixation measures will be constant to this baseline measurement. If the head is stabilised with a bite-plate, examiners can detect with the Goldmann perimeter's telescope rapid flick saccades $\geqslant 1^{\circ}$ of arc or slow motion drifts which can occur at a rate 
as slow as about $1^{\prime}$ of arc/s. This is best understood when Situation $\mathrm{C}$ is compared to Situations $\mathrm{A}$ and $\mathrm{B}$. (a) In Situation $A$ the head and eye are both in proper alignment.

The (1) fixation point (X) is imaged on the fovea (O) in primary position, (2) allowing for the detection of some peripherally imaged stimulus $(O)$ at some distance from the fovea, while (3) the eye (pupil) is imaged as properly aligned in the crosshairs of the examiner's telescope.

(b) In Situation $B$ the eye is in improper alignment and it is detected by the examiner. The eye has rotated from primary position (no head movements are made), thus (1) the fixation point (X) no longer corresponds to fovea $(\bullet),(2)$ allowing for easier detection of the peripherally imaged stimulus (same stimulus position as in Situation A) resulting from the reduction of the distance between the fovea and the peripheral stimulus $(0)$, while (3) the eye is imaged in the cross-hairs of the examiner's telescope in an improper position.

(c) In Situation $C$ the eye is in improper alignment but remains undetected by the examiner. The eye has rotated from primary position (eye and/or head rotation) and the head has moved over slightly in a lateral direction; therefore, (1) the fixation point (X) as in Situation B still no longer corresponds to the fovea (O), (2) allowing for easier detection of the peripherally imaged stimulus resulting from the reduction of the distance between the fovea and the peripheral stimulus $(O)$, while (3) the eye is improperly observed to be perfectly aligned in the crosshairs of the examiner's telescope. This occurs when the examiner has not detected an obvious eye movement (such as a slow drift) or has been momentarily inattentive during a relatively fast eye movement and sees that the eye is not in the cross-hairs. He may then assume that the patient's head has moved; and therefore remotely readjust the patient's head so that his eye is in what appears to be proper alignment (Situation A). The only way that the examiner can determine that the eye is eccentrically fixating would be to "remember" the eye's overall position relative to the patient's eye lids, independent of the eye's position to the cross-hairs. This, however, is clinically difficult for the examiner to define for more than a few minutes because of potentially varying and undifferentiated lid movements and head movements which are allowed by the chin-rest.

A full mouth impression bite-plate, on the other hand, typically stabilises head rotations to within $30^{\prime}-50^{\prime}$ of arc. ${ }^{29}$ In this manner, Situation $C$ is kept to a minimum, allowing the examiner to discriminate between eye movement compensation as manifested by eccentric fixation (Situation B) and proper foveal fixation (Situation $A$ ) by use of the telescope.
When we re-examined our patients with a biteplate after they had been trained for some time on a chin-rest (head-eye stabilisation condition $\mathrm{CB}$ in table I), we found that three patients (GA, VB, VM) had apparently developed the eye movement strategy of making undetected eccentric fixations over the course of many training sessions. The results of patient GA are shown in fig. 3. Initial testing with a chin-rest resulted in the isopter plot shown by the filled circles $(\Theta)$. The open circles $(O)$ show his training results after 75 sessions with the chin-rest. It would appear that marked changes had occurred in GA's visual fields. The other (OD) eye, (not shown, had similar results). GA was then examined once again, but with the use of a biteplate. The open triangles $(\triangle)$ represent these results. When these results are compared to the first day of testing, it is clear that the visual fields of GA had in fact not improved. He had apparently been using eccentric fixation as a means of visual field compensation.

Zihl and von Cramon report monitoring eye position with an infrared camera and monitor while the patients' head is stabilised with a chin-rest. ${ }^{15}$ Contrary to this, we believe that infrared camera monitors, infrared eye trackers, electrooculograms (EOG), or any other type of eye monitoring systems that do not also involve the complete stabilization of the head (that is with a bite-plate or similar device) cannot be calibrated for long-term, inter-session use. It is academic which eye monitoring system is used. Without a complete head stabilisation system $\triangle$ Zihl and von Cramon have the potential for thiso same problem; that is, relatively long-term eccentric fixations as an eye movement compensation strategy may have in part or wholly been responsible for their results.

Compensatory eccentric fixations also could have been responsible for Zihl and von Cramon's observations (as well as our own) that "The diminution of contrast sensitivity is marked when the patient does not know where the target will appear and thus cannot direct his attention to that area of the visual field." 16 An alternative to this "attention" hypothesis is that compensatory eccentric fixation (Situation C) may have been responsible for their patient's improvement, which was confined to the trained visual field area". ${ }^{16}$ Eccentric fixation would not be of value when randomly positioned target detection was required, since these relatively large and rapid eye movements probably would have been detected with their eye monitoring system, as in Situation B. Attention must certainly play a part in detection; the question remains, however, as to whether or not eye movements were associated with these attentional factors. 
Conclusion

Any combination of the following factors may have influenced Zihl and von Cramon' $\mathrm{s}^{15-17}$ reported trained visual field increases in their hemianopic patients: (a) reliance on subjective impressions; (b) large visual stimuli response variability; (c) changes in detection strategies with practice; and (d) compensatory eccentric fixation. When we controlled or made allowance for these variables, no significant visual field increases were found in our cortically blind patients. Therefore, we must seriously question Zihl and von Cramon's conclusions concerning the neurological mechanisms which they suggest are responsible for their patients' supposed visual field increases. Until additional studies which control for compensation strategies are brought forth, we must support the opinion that lesions to the striate cortex in humans result in permanent blindness.

We thank Ersebet Marosi and Lucia Septien, for their assistance on this project and Renie Davison for her help in editing the manuscript. We also thank Robert T. Knight, MD in the Department of Neurology, Martinez Veterans Administration Medical Center for his help in finding patients for this study and Dr. Chris Johnson, Department of Ophthalmology, University of California at Davis for his procedural assistance.

\section{References}

' Bergmann PS. Cerebral Blindness. Arch Neurol Psychiatry 1957;78:568-84.

${ }^{2}$ Symonds C, Mackenzie J. Bilateral loss of vision from cerebral infarction. Brain 1957;80:415-55.

${ }^{3}$ Walsh FB, Hoyt WF. Clinical Neuro-ophthalmology. Baltimore: Williams \& Wilkins, Vol. I, 1957:78-84.

${ }^{4}$ Brindley GS, Gautier-Smith PC, Lewin W. Cortical blindness and the functions of the non-geniculate fibres of the optic tracts. J Neurol Neurosurg Psychiatry 1969;32:259-64.

5 Braak JWG ter, Schenk VWD, Vliet AGM van. Visual reactions in a case of long-lasting cortical blindness. J Neurol Neurosurg Psychiatry 1971;34:140-7.

- Brindley GS, Janota I. Observations on cortical blindness and on vascular lesions that cause loss of recent memory. J Neurol Neurosurg Psychiatry 1975;38:459-64.

${ }^{7}$ Richards W. Visual processing in scotoma. Exp Brain Res 1973; 17:333-47.

${ }^{8}$ Poppel E, Held R, Frost D. Residual visual function after brain wounds involving the central visual pathways in man. Nature 1973;243:295-6.

9 Weiskrantz L, Warrington EK, Sanders MD, Marshall J. Visual capacity in the hemianopic field following a restricted occipital ablation. Brain 1974;97:709-28.

${ }^{10}$ Perenin MT, Jeannerod M. Residual vision in cortically blind hemifields. Neuropsychologia 1975;13:1-7.

${ }^{11}$ Cowey A, Weiskrantz L. A perimetric study of visual field defects in monkeys. QJ Exp Psychol 1963; 15:91-115.

${ }_{12}$ Cowey A. Perimetric study of field defects in monkeys after cortical and retinal ablations. QJ Exp Psychol 1967;19:232-45.

${ }^{13}$ Mohler CW, Wurtz RH. Role of striate cortex and superior colliculus in visual guidance of saccadic eye movements in monkeys. J Neurophysiol 1977; 40:74-94.

${ }^{14}$ Weiskrantz L, Cowey A, Passingham C. Spatial responses to brief stimuli by monkeys with striate cortex ablations. Brain 1977; 100:655-70.

${ }^{15} \mathrm{Zihl}$ J. Recovery of visual functions in patients with cerebral blindness. Exp Brain Res 1981;24:159-69.

${ }^{16}$ Zihl J, von Cramon D. Restitution of visual function in patients with cerebral blindness. J Neurol Neurosurg Psychiatry 1979;42:312-22.

${ }^{17}$ Zihl J, von Cramon D. Restitution of visual field in patients with damage to the geniculostriate visual pathway. Hum Neurobiol 1982;1:5-8.

${ }^{18}$ Wurtz RH, Goldberg ME. The primate superior colliculus and the shift of visual attention. Invest Ophthalmol 1972;11:441-450.

${ }^{19}$ Lynch JC, Mountcastle VB, Talbot WH, Yin TCT Parietal lobe mechanisms for directed visual attention. J Neurophysiol 1977;4:362-89.

${ }^{20}$ Mountcastle VB. Brain mechanisms for directed visual attention. J R Soc Med 1978;41:14-28.

${ }^{21}$ Bach-y-Rita P. Central nervous system lesions: sprouting and unmasking in rehabilitation. Arch Phys Med Rehabil 1981a;62:413-7.

${ }^{22}$ Bach-y-Rita P. Brain plasticity as a basis of the development of rehabilitation procedures for hemiplegia. Scand J Rehabil Med 1981b;13:73-83.

${ }^{23}$ Bebie H, Frankhauser F, Spahr J. Static Perimetry: Strategies. Acta Ophthalmol 1976;54,3:325-38.

${ }^{24}$ Cornsweet TN. The staircase method in psychophysics. Am J Psychol 1962;75:485-91.

${ }^{25}$ Troxler D. Uber das Verschwinden gegebener Gegenstande innerhalb unseres Gesichtskreises. Himly $V$. Schmidt's ophthalmologische Bibliothek 1802;2:2.

26 Johnson CA, Keltner JL, Balestrery FG. Static and acuity profile perimetry at various adaptation levels. Documenta Ophthal 1981;50:371-88.

${ }^{27}$ Aulhorn E, Harms H. Visual perimetry. In: LM Hurvich, DJ, Hurvich eds. Handbook of Sensory Physiology (Vol VII/4) Visual psychophysics. Berlin: Springer-Verlag, 1972:56-77.

${ }^{28}$ Moreland JD. Peripheral colour vision, In LM Hurvich, DJ Hurvich eds. Handbook of Sensory Physiology (Vol VII/20) Visual psychophysics. Berlin: SpringerVerlag, 1972:517-36.

${ }^{29}$ Ditchburn RW. Eye-movements and Visual Perception Oxford: Clarendon Press, 1973:47-8.

${ }^{30}$ Balliet R, Nakayama K. Training of voluntary torsion. Invest Ophthalmol Vis Sci 1978;17,4:303-14.

${ }^{31}$ Harms H. Die praktische Bedeutung quantitativer Perimetrie. Klin Mbl Augenheilkunde 19,52;121: 683-92.

${ }^{32}$ Weekers R, Lavergne G. Applications cliniques de la 
perimetric statique. Bull Soc Belge Ophthalmol 1958;119:418-30.

${ }^{33}$ Sloan LL. Area and luminance of test object as variables in examination of the visual field by projective perimetry. Vision Res $1961 ; 121: 138-43$.

${ }^{34}$ Campion J, Latto R, Smith YM. Is blindsight due to scattered light, spared cortex and near-threshold effects? The Behavioral and Brain Sciences Cambridge: Cambridge Univ. Press, 1983:1-64.

${ }^{35}$ Zihl J. "Blindsight": improvements of visually guided eye movements by systematic practice in patients with cerebral blindness. Neuropsychologia 1980;18:71-7.

${ }^{36} \mathrm{Zihl} \mathrm{J}$, von Cramon D. Registration of light stimuli in the cortically blind hemifield and its effect on localization. Behav Brain Res 1980;1:287-98.

${ }^{37}$ Wyszecki G, Stiles WS. Color science: Concepts and methods, Quantitative Data and Formulas. New York: John Wiley and Sons, Inc., 1967:219-21.

${ }^{38}$ Frankhauser F, Haeberlin H. An Estimate of the Falsifying Effects of Stray Light in Perimetry. Doc Ophthalmol 1980;50:143-67.
${ }^{39}$ Low FN. Some characteristics of peripheral visual performance. Am J Physiol 1946; 140: 83-88.

${ }^{40}$ Low FN. Peripheral visual acuity. Arch Ophthalmol 1951;45:577-93.

${ }^{4}$ Saugstad P, Lie I. Training of peripheral visual acuity. Scand J Psychol 1964;5:218-24.

42 Johnson CA, Leibowitz HW. Practice effects for visual resolution in periphery. Perception Psychophysics 1979;25(5):439-42.

${ }^{43}$ Swets JA, Tanner WP Jr, Birdsall TG. Decision processes in perception. Psychol Rev 1961;68:301-40.

${ }^{44}$ Nachmias J. Signal detection theory and its application to problems in problems in vision. In: Hurvich LM, Hurvich DJ, eds. Handbook of sensory physiology (Vol VII/3) Visual psychophysics. Berlin: SpringerVerlag, 1972:38-55.

${ }^{45}$ Meienberg O, Zangemeister WH, Rosenberg M, Hoyt WF, Stark L. Saccadic eye movement strategies in patients with homonymous hemianopia. Ann Neurol 1981;9(6):537-44. 